\title{
An access to some functionalized azocine derivatives
}

\author{
Laurent Gil, ${ }^{\mathrm{a}, *}$ Rossimiriam Pereira de Freitas Gil, ${ }^{\mathrm{b}}$ Daniela Cristina dos Santos ${ }^{\mathrm{b}}$ \\ and Christian Marazano ${ }^{\mathrm{c}}$ \\ ${ }^{a}$ Departamento de Química, Instituto de Ciências Exatas e Biológicas, UFOP, Brazil \\ ${ }^{\mathrm{b}}$ Departamento de Quimica, Instituto de Ciências Exatas, UFMG, Brazil \\ 'Institut de Chimie des Substances Naturelles, CNRS, 91198 Gif-sur-Yvette, France
}

Received 30 March 2000; accepted 14 June 2000

\begin{abstract}
The syntheses, from readily accessible 3-alkyl-4-methoxy-1,3,4,5-tetrahydropyridine $\mathbf{1}$, of functionalized 1,6,7,8-tetrahydroazocine 7 and 1,2,7,8-tetrahydroazocine 9 are reported. (C) 2000 Published by Elsevier Science Ltd.
\end{abstract}

Keywords: azocines; nitrogen heterocycles.

Eight-membered nitrogen heterocycles constitute an important class of compounds, especially in view of their pharmacological properties. ${ }^{1}$ These derivatives are generally difficult to obtain ${ }^{2}$ and, accordingly, relatively few methods are available for their preparation. This is especially the case of highly functionalized derivatives or derivatives suitable for further chemoselective reactions.

We recently reported ${ }^{3}$ that tetrahydropyridines $\mathbf{1}$ (Scheme $1, \mathrm{R}^{1}$ and $\mathrm{R}^{2}=$ alkyl group) are good precursors of 3-alkyl 1,6-dihydropyridines 2 which were too unstable to be isolated, but could be trapped with common dienophiles to produce isoquinuclidine derivatives 3 . As a continuation of our studies concerning the reactivity of derivatives $\mathbf{1}$, we now report that the reaction of these reactive intermediates with ethyl propiolate gave highly functionalized azocines heterocycles $\mathbf{4}$ in high yield.

Dihydropyridinium salt 5 (Scheme 2) was obtained from the corresponding pyridinium salt following well-established procedures. ${ }^{4}$ The reaction of salt $\mathbf{5}$ with sodium methoxide in methanol gave adduct 1a in good yield. ${ }^{3}$ Adduct 1a, when treated with ethyl propiolate in refluxing acetonitrile, gave the functionalized 1,6,7,8-tetrahydroazocine 7 in $90 \%$ yield. It is believed that azocine formation involves an initial [2+2] cycloaddition ${ }^{3,6}$ reaction between the enamine 1a to give the cyclobutene intermediate $\mathbf{6}$, followed by an electrocyclic ring opening to give the azocine system.

\footnotetext{
* Corresponding author. Fax: +55 031551 1707; e-mail: laurent@iceb.ufop.br 


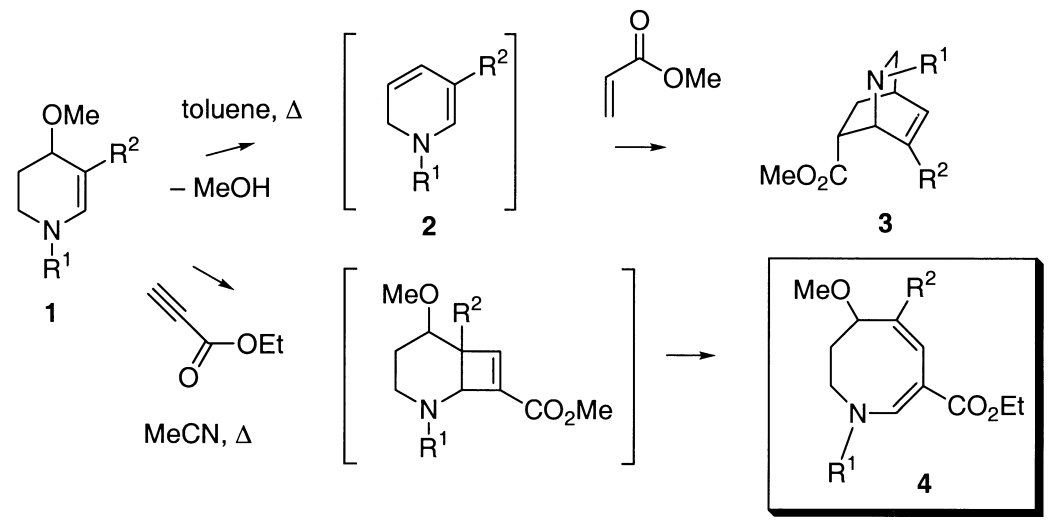

Scheme 1.
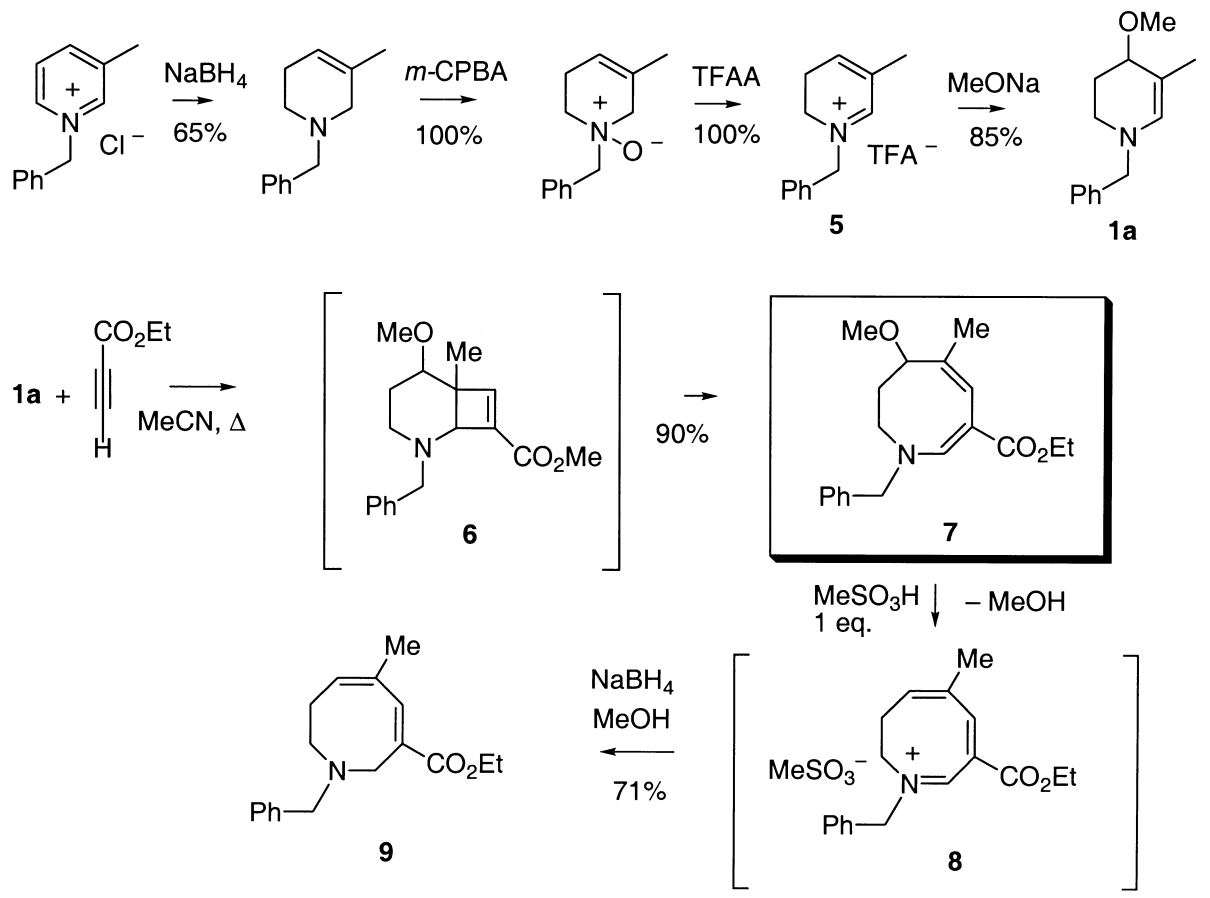

Scheme 2 .

Azocine 7 was treated with 1 equivalent of methanesulfonic acid to give, presumably, an iminium salt (8, not isolated). Reduction of this salt with $\mathrm{NaBH}_{4}$ in methanol finally gave $1,2,7,8$ tetrahydroazocine $\mathbf{9}$.

Further studies to extend this approach to other azocines are currently in progress.

\section{Acknowledgements}

We thank FAPEMIG-MG and CAPES, Brazil for financial support. 


\section{References}

1. Evans, P. A.; Holmes, A. B. Tetrahedron 1991, 47, 9131-9166.

2. For previous related approaches, see: Lallemand, M.-C.; Chiadmi, M.; Tomas, A.; Kunesch, N.; Husson, H.-P. Tetrahedron Lett. 1995, 36, 2053--2056, and references cited therein.

3. Gil, L.; Gateau-Olesker, A.; Marazano, C.; Das, B. C. Tetrahedron Lett. 1995, 36, 707-710.

4. Grierson, D. S.; Harris, M.; Husson, H. P. J. Am. Chem. Soc. 1980, 102, 1064-1082.

5. Selected data for 7: $\mathrm{mp} 112^{\circ} \mathrm{C}$ (ether-heptane); IR $\left(\mathrm{cm}^{-1}\right)$ 2981, 2931, 1685, 1605, 1577, 1453, 1421, 1364, 1291, 1251, 1196; ${ }^{1} \mathrm{H}$ NMR $\left(\mathrm{CDCl}_{3}, 200 \mathrm{MHz}\right) \delta 1.03(1 \mathrm{H}, \mathrm{m}), 1.29(3 \mathrm{H}, \mathrm{t}, J=7.1 \mathrm{~Hz}), 1.57(1 \mathrm{H}, \mathrm{tt}, J=12.6,5 \mathrm{~Hz}), 1.64$ $(3 \mathrm{H}, \mathrm{d}, J=1.6,1.8 \mathrm{~Hz}), 2.85(1 \mathrm{H}, \mathrm{m}), 3.24(3 \mathrm{H}, \mathrm{s}), 3.60(1 \mathrm{H}, \mathrm{m}), 4.00-4.40(3 \mathrm{H}, \mathrm{m}), 4.20(2 \mathrm{H}, \mathrm{q}, J=7.1 \mathrm{~Hz}), 6.28$ $(1 \mathrm{H}, \mathrm{m}), 7.23-7.40(5 \mathrm{H}, \mathrm{m}), 7.61(1 \mathrm{H}, \mathrm{s}) ;{ }^{13} \mathrm{C} \mathrm{NMR}\left(\mathrm{CDCl}_{3}, 50.32 \mathrm{MHz}\right) \delta 14.74,16.82,21.12,44.98,57.07,59.82$, $61.51,79.21,95.26,122.39,127.78,128.18,128.93,131.33,136.61,148.99,169.88$; HRMS calcd for $\mathrm{C}_{19} \mathrm{H}_{25} \mathrm{NO}_{3}$ : 315.1835; found: 315.1842 ; anal. calcd for $\mathrm{C}_{19} \mathrm{H}_{25} \mathrm{NO}_{3}: \mathrm{C}, 72.35 ; \mathrm{H}, 7.99 ; \mathrm{N}, 4.44 ; \mathrm{O}, 15.22$; found: $\mathrm{C}, 72.07$; $\mathrm{H}$, 8.24; N, 4.53; O, 15.03 .

6. Weinstein, B.; Lin, L.-C. C.; Fowler, F. W. J. Org. Chem. 1980, 45, 1657-1661. 